CLINICAL STUDY

\title{
Bone mineral density in bulimic women - influence of endocrine factors and previous anorexia
}

\author{
Sabine Naessén ${ }^{1}$, Kjell Carlström ${ }^{1}$, Rolf Glant ${ }^{3}$, Hans Jacobsson ${ }^{2}$ and Angelica Lindén Hirschberg ${ }^{1}$ \\ Departments of ${ }^{1}$ Obstetrics and Gynecology and ${ }^{2}$ Radiology, Karolinska University Hospital, SE-17176 Stockholm, Sweden and ${ }^{3}$ Neurotec Department, \\ Section of Psychiatry, Karolinska Institutet, SE-17177 Stockholm, Sweden
}

(Correspondence should be addressed to S Naessén; Email: sabine.naessen@karolinska.se)

\begin{abstract}
Objective: Data concerning bone mineral density (BMD) in bulimia nervosa are contradictory and include both low and normal values. The aim of the present study was to elucidate possible endocrineand nutrition-related factors predicting BMD in bulimic women.

Design: Cross-sectional study.

Methods: Seventy-seven bulimic patients and 56 age- and body mass index (BMI)-matched healthy controls were examined with respect to BMD (dual energy X-ray absorptiometry) and to serum levels of hormones and metabolic factors.

Results: Bulimics had significantly lower spinal BMD and higher frequency of osteopenia in the total body than controls. Furthermore, bulimic women had significantly lower levels of estradiol-17 $\beta$ and free thyroxine and significantly higher cortisol levels compared with controls. Among the bulimics, $31.2 \%$ had present menstrual disturbance, $51.9 \%$ had a history of amenorrhea and $23.4 \%$ had previous anorexia nervosa. Subgroups of bulimics with a history of amenorrhea and previous anorexia nervosa had significantly lower total and spinal BMD than controls, whereas those without such history did not differ from the controls. In univariate analysis, a history of amenorrhea, cortisol, testosterone, previous anorexia nervosa, and BMI showed significant associations with spinal BMD. Multiple regression analysis including all significant variables revealed previous anorexia nervosa to be the strongest determinant of spinal BMD, accounting for $34 \%$ of the variance, while associations between endocrine factors and BMI disappeared.

Conclusions: Low bone mass in bulimics may be explained by previous anorexia nervosa, whereas endocrine variables related to BMD seem to be secondary determinants that are dependent on previous anorexia nervosa and BMI.
\end{abstract}

European Journal of Endocrinology 155 245-251

\section{Introduction}

Low bone mass in eating-disordered women is well recognized, but data concerning bone mineral density (BMD) in bulimia nervosa are contradictory. Low BMD is reported in some studies, thus indicating that bulimic women constitute a risk group for osteoporosis (1-4), whereas others have reported normal BMD in bulimic women (5-7). Twenty-five to thirty percent of bulimic patients have a previous history of anorexia nervosa (8). This eating disorder is associated with an apparent loss of bone mass, particularly of trabecular bone, and up to $50 \%$ of anorectic patients have osteoporosis in the lumbar spine (9). Bone loss in anorexia nervosa is considered to be secondary to a catabolic state caused by restrictive eating, a low calcium intake and estrogen deficiency leading to amenorrhea $(9,10)$.

Bulimia nervosa is associated with several hormonal aberrations that may affect bone mass. Menstrual disturbances and low levels of estradiol are common
(11-14), although most bulimics are of normal weight. Furthermore, elevated cortisol and adrenocorticotropic hormone (15-17) have been reported in bulimia nervosa, suggesting an increased activity of the hypothalamic-pituitary-adrenal axis. Hypercortisolism is a well-known endocrine factor affecting the skeleton negatively and may eventually lead to osteoporosis. There are also reports of increased androgen levels in bulimic women, such as in the polycystic ovary syndrome (18-20), which should have a positive influence on bone mass. Furthermore, low levels of thyroid hormones, considered to be a consequence of the temporary starvation periods related to this disease, have been demonstrated in bulimia nervosa $(12,21$, 22). Thyroid hormones are essential for maintaining skeletal growth and remodeling (23).

It is still unclear whether bulimia is associated with low bone mass or not, and to our knowledge, there is no previous study comparing the influence of the abovementioned endocrine factors and of previous anorexia 
nervosa on BMD in bulimic women. We, therefore, aimed to investigate possible associations between BMD and these factors in a large group of bulimic women and in healthy-matched controls.

\section{Materials and methods}

\section{Subjects}

Women with bulimia and healthy regularly menstruating control subjects, matched for age (range 18-40 years) and body mass index (BMI; range $19-33 \mathrm{~kg} / \mathrm{m}^{2}$ ) were recruited by media advertising and among students and hospital staff. One hundred and fifty-two potential bulimics and controls were interviewed by a trained research psychologist using a semi-structured clinical interview (24). Forty-six women fulfilled the criteria for bulimia nervosa, including frequent binge eating episodes and the regular use of inappropriate compensatory behaviors, such as self-induced vomiting, laxative abuse, or periods of fasting to prevent increase in body weight, and 31 had an eating disorder not otherwise specified (EDNOS, partial bulimia nervosa) with bulimia as the predominant symptom, as defined by the Diagnostic and Statistical Manual of Mental Disorders, fourth edition (DSM-IV); American Psychiatric Association, 1994. A total of 77 bulimic women and 56 controls were included in the study.

Information about history of anorexia nervosa as defined by the DSM-IV criteria and pattern of menstrual periods was provided by the women. Menstrual status was classified as regular monthly periods with intervals of 24-32 days; amenorrhea, no bleeding for the last 3 months; or oligomenorrhea, periods at an interval exceeding 6 weeks. All subjects were free of any medication including psychotropic drugs and oral contraceptives at least 3 months before the study. Smoking, defined as a minimum of one cigarette daily, was not an exclusion criterion. Apart from present and previous eating disorders, neither bulimics nor controls have had any other conditions known to cause loss of bone mass. The study was approved by the local Ethics Committee at the Karolinska University Hospital, and written consent was obtained from all women before participation.

\section{Study design}

Subjects visited the Women's Health Clinical Research Unit, Department of Obstetrics and Gynecology, Karolinska University Hospital at $0730 \mathrm{~h}$ after an overnight fast. Body weight and height and blood pressure were measured in a standardized manner. A fasting blood sample was collected at $0800 \mathrm{~h}$, in a resting state, from a peripheral vein in the early follicular phase of the menstrual cycle (cycle days 1-5) in menstruating subjects, while amenorrheic women were investigated on an arbitrary day.

\section{Body mineral density}

Determination of BMD was performed by dual-energy X-ray absorptiometry (DXA) using a Hologic QDR4500A scanner (Hologic, Inc., Bedford, MA, USA). The reproducibility of whole body BMD is calculated as $<0.01 \mathrm{~g} / \mathrm{cm}^{2}$ or 0.1 s.D. $(25,26)$. The examination was a whole-body scan. In this scan, the lumbar spine (L1-L4) and both legs were interactively defined and the regional BMD assessed using the standard software. Mean BMD values of both legs were calculated, since the area differences were negligible.

The prevalence of low BMD of the total body was defined as osteopenia if the $T$-score was between -1 and -2.5 s.D. of that for young adults (peak bone mass); and osteoporosis if the T-score was below -2.5 s.D., according to the World Health Organization (WHO), and as a Z-score below -2 s.D. of the age-matched mean according to the International Society for Clinical Densitometry guidelines for defining low BMD in premenopausal women (27). The T- and Z-scores were estimated using mean BMD and s.D. values supplied by the Hologic equipment manufacturer.

\section{Analytical methods}

Serum estradiol-17 $\beta\left(\mathrm{E}_{2}\right)$ and testosterone were determined by RIA using commercial kits, 'Spectria' $\left(\mathrm{E}_{2}\right.$; Orion Diagnostica OY, Esbo, Finland) and 'Coat-aCount Testosterone' (Diagnostic Products Corp., Los Angeles, CA, USA). Serum cortisol, sex hormonebinding globulin (SHBG), insulin-like growth factor-I (IGF-I), thyroid-stimulating hormone (TSH), and free thyroxine $\left(\mathrm{fT}_{4}\right)$ were determined by direct chemiluminescence enzyme immunoassay using commercial kits, Immulite (Diagnostic Products Corp., Los Angeles, CA, USA). The values of TSH are expressed as mIU/l of the WHO 2nd IRP TSH 80/558.

Detection limits and within and between assay coefficients of variation were $5 \mathrm{pmol} / \mathrm{l}, 3$ and $6 \%$ for $\mathrm{E}_{2} ; 0.1 \mathrm{nmol} / \mathrm{l}, 6$ and $10 \%$ for testosterone; $5.5 \mathrm{nmol} / \mathrm{l}$, 7.8 and $7.8 \%$ for cortisol; $0.2 \mathrm{nmol} / \mathrm{l}, 6.5$ and $8.7 \%$ for SHBG; $20 \mu \mathrm{g} / \mathrm{l}, 3.6$ and $6.6 \%$ for IGF-I; $0.002 \mathrm{mIU} / \mathrm{l}, 5$ and $10 \%$ for TSH; and $1.9 \mathrm{pmol} / \mathrm{l}, 4.5$ and $5.6 \%$ for $\mathrm{fT}_{4}$ respectively.

Apparent concentrations of free testosterone (fT) were calculated from values for total testosterone, SHBG, and a fixed albumin concentration of $40 \mathrm{~g} / \mathrm{l}$ by successive approximation using a computer program based upon an equation system derived from the law of mass action (28).

\section{Statistical analysis}

Normally distributed data are presented as arithmetic means and S.D. or 95\% confidence intervals, and otherwise as medians and ranges. Some of the variables were log-transformed before the formal analyses, since 
the distribution was positively skewed. Comparisons between bulimic women and controls were performed with the $t$-test for independent samples. The $\chi^{2}$ and Fisher's exact test were used to analyze variables measured on a nominal scale. When comparing DXA values in subgroups of bulimics with those in controls, statistical analyses were adjusted for BMI using analysis of covariance. Correlations were calculated with Pearson's product moment correlation coefficient. Forward stepwise multiple linear regression analysis was used to evaluate to what extent the variation in spinal BMD could be explained by endocrine- and nutrition-related variables. For the stepwise selection, we used a criterion for entry of a $P$ value $<0.10$ and for removal of a $P$ value $>0.10$. The significance level was set at 0.05 .

\section{Results}

Clinical data and BMD in bulimic women and controls are presented in Table 1. Spinal BMD was significantly lower $(P<0.01)$ and total BMD tended to be lower $(P=0.07)$ in bulimics compared with controls, whereas BMD in legs was not significantly different between groups. Osteopenia in total body was significantly more frequent in women with bulimia than controls $(P<0.05)$. Osteoporosis and a Z-score below -2 were found in two bulimics, but not in controls. There was a significantly higher frequency of smokers in the bulimics compared with controls. Fifty percent of the smokers in both groups consumed 10-20 cigarettes daily.

Among the 77 bulimics, 24 (31.2\%) had present menstrual disturbance, of which, 18 had oligomenorrhea and six had amenorrhea. Duration of present menstrual disturbance was 11 (1-17) years and showed a highly significant positive correlation with duration of bulimia

Table 1 Clinical data and bone mineral density (BMD) in bulimic women and controls. Values are given as mean \pm s.D. or median and range.

\begin{tabular}{lcc}
\hline & $\begin{array}{c}\text { Bulimics } \\
(n=77)\end{array}$ & $\begin{array}{c}\text { Controls } \\
(n=56)\end{array}$ \\
\hline Age (years) & $27.5 \pm 5.3$ & $28.6 \pm 5.8$ \\
Debut of bulimia (age) & $17(11-33)$ & - \\
Duration of bulimia (years) & $9.5(1-23)$ & - \\
Smoking & $29 / 77$ & $9 / 56$ \\
BMl $\left(\mathrm{kg} / \mathrm{m}^{2}\right)$ & $22.0(19.0-33.0)$ & $22.2(19.0-29.5)$ \\
Total body fat $(\%)$ & $29.6 \pm 7.7$ & $29.7 \pm 6.0$ \\
Lean body mass $(\mathrm{kg})$ & $41.3 \pm 4.3$ & $40.6 \pm 4.4$ \\
BMD total body $\left(\mathrm{g} / \mathrm{cm}^{2}\right)$ & $1.12 \pm 0.09$ & $1.14 \pm 0.07$ \\
BMD spine $\left(\mathrm{g} / \mathrm{cm}^{2}\right)$ & $1.06 \pm 0.14^{\star *}$ & $1.11 \pm 0.12$ \\
BMD legs $\left(\mathrm{g} / \mathrm{cm}^{2}\right)$ & $2.36 \pm 0.22$ & $2.42 \pm 0.18$ \\
Osteopenia total body & $10 / 77$ & $1 / 56$ \\
Osteoporosis total body & $2 / 77$ & 0 \\
$Z$-score total body $<-2$ s.D. & $2 / 77$ & 0 \\
\hline
\end{tabular}

${ }^{* \star} P<0.01$
( $r=0.87, P<0.001$ ). Subgroups of bulimics with present menstrual disturbance (oligomenorrhea and amenorrhea) and with regular menses, had significantly lower spinal BMD than controls $(1.05 \pm 0.12$ vs $1.12 \pm 0.12 \mathrm{~g} / \mathrm{cm}^{2}, \quad P<0.05$ and $1.06 \pm 0.12 \mathrm{vs}$ $1.12 \pm 0.12 \mathrm{~g} / \mathrm{cm}^{2}, P<0.01$ respectively). A history of amenorrhea (including those with present amenorrhea) was reported by $51.9 \%$ of the patients. These bulimics had significantly lower spinal BMD compared with controls and compared with bulimics who had never had amenorrhea (Fig. 1a). This was also true for total BMD $\left(1.09 \pm 0.08\right.$ vs $1.15 \pm 0.07 \mathrm{~g} / \mathrm{cm}^{2}, P<0.001$ and $1.09 \pm 0.08$ vs $1.15 \pm 0.08 \mathrm{~g} / \mathrm{cm}^{2}, P<0.001$ respectively). The subgroup of bulimics without a history of amenorrhea had values of total and spinal BMD
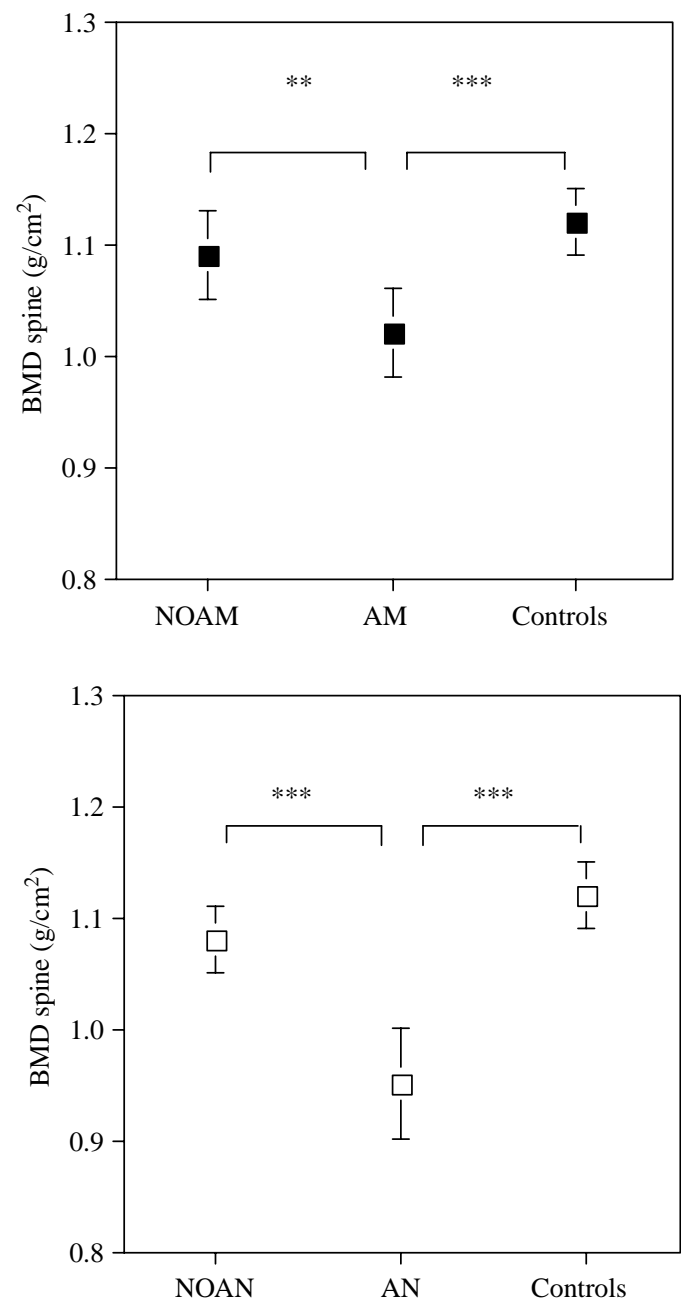

Figure 1 (a) Spinal bone mineral density (BMD) in subgroups of bulimic women without (NOAM) and with a history of amenorrhea (AM) compared with healthy controls. Values are means and $95 \%$ confidence intervals. Significant differences are denoted by ${ }^{\star \star} P<0.01$ and ${ }^{* * *} P<0.001$. (b) Spinal BMD in subgroups of bulimic women without (NOAN) and with previous anorexia nervosa (AN) compared with healthy controls. Values are means and $95 \%$ confidence intervals. Significant differences are denoted by ${ }^{\star \star \star} P<0.001$. 
comparable to controls. None of the controls had a history of amenorrhea.

Levels of hormones and SHBG in bulimic women and controls are presented in Table 2. Bulimic women had significantly lower levels of $\mathrm{E}_{2} \quad(P<0.001)$ and $\mathrm{fT}_{4}$ $(P<0.001)$ than controls. Furthermore, bulimics had significantly higher serum cortisol levels $(P<0.01)$ compared with controls. There were no significant differences between groups in testosterone, SHBG, fT, IGF-I, or TSH levels.

Correlations between BMD and endocrine variables in women with bulimia are shown in Table 3. Present menstrual dysfunction (oligomenorrhea and amenorrhea) showed no correlation with BMD, whereas a history of amenorrhea correlated negatively with total and spinal BMD $(P<0.01$ respectively $) . E_{2}$ levels displayed a tendency towards a positive correlation with spinal BMD $(P=0.07)$. Cortisol levels were negatively correlated with total and spinal BMD $(P<0.05$ respectively), whereas testosterone and $\mathrm{fT}$ were positively correlated with spinal BMD $(P<0.05$ respectively). There were no correlations between BMD and IGF-I or thyroid hormones.

Eighteen of the bulimic women (23.4\%) had a history of anorexia nervosa. The median duration of anorexia was 3.5 (1-7) years and their minimum BMI was 15.8 (12.1-17.5) $\mathrm{kg} / \mathrm{m}^{2}$. Bulimics with past anorexia nervosa had significantly lower spinal BMD compared with controls and compared with bulimics without a history of anorexia nervosa (Fig. 1b). This was also true for total BMD $\left(1.05 \pm 0.08\right.$ vs $1.15 \pm 0.07 \mathrm{~g} / \mathrm{cm}^{2}, P<0.001$ and $1.05 \pm 0.08$ vs $1.14 \pm 0.08 \mathrm{~g} / \mathrm{cm}^{2}, P<0.001$ respectively). There were no associations between duration of anorexia and BMD (data not shown). Bulimics without a history of anorexia nervosa had values of total and spinal BMD comparable to controls. However, they still had significantly lower levels of $E_{2}(87$ (7-350) pmol/l, $P<0.05)$ and $\mathrm{fT}_{4}(13.0 \pm 1.9 \mathrm{pmol} / \mathrm{l}, \quad P<0.01)$ and significantly higher levels of cortisol $(461 \pm 140 \mathrm{nmol} / \mathrm{l}$,

Table 2 Levels of hormones and SHBG in bulimic women and controls. Values are given as mean \pm S.D. or median and range.

\begin{tabular}{|c|c|c|}
\hline & $\begin{array}{c}\text { Bulimics } \\
(n=77)\end{array}$ & $\begin{array}{c}\text { Controls } \\
(n=56)\end{array}$ \\
\hline $\begin{array}{l}\text { Estradiol-17 }(\mathrm{E} 2) \\
(\mathrm{pmol} / \mathrm{l})\end{array}$ & $79(7-510)^{\star \star \star}$ & $109(31-519)$ \\
\hline Cortisol (nmol/l) & $473 \pm 142^{* *}$ & $394 \pm 141$ \\
\hline Testosterone $(\mathrm{nmol} / \mathrm{l})$ & $1.2 \pm 0.6$ & $1.0 \pm 0.4$ \\
\hline SHBG $(\mathrm{nmol} / \mathrm{l})$ & $45.9(14.4-120)$ & $50.9(25.2-96.8)$ \\
\hline $\begin{array}{l}\text { Free testosterone }(\mathrm{fT}) \\
(\mathrm{pmol} / \mathrm{l})\end{array}$ & $20.0 \pm 11.7$ & $16.8 \pm 7.4$ \\
\hline $\begin{array}{l}\text { Insulin-like growth } \\
\text { factor-I (IGF-I) }(\mu \mathrm{g} / \mathrm{l})\end{array}$ & $231 \pm 70$ & $229 \pm 68$ \\
\hline TSH $(\mathrm{mIU} / \mathrm{l})$ & $1.6(0.2-12.0)$ & $1.5(0.5-3.9)$ \\
\hline $\begin{array}{l}\text { Free thyroxine (fT4) } \\
(\mathrm{pmol} / \mathrm{l})\end{array}$ & $12.8(9.4-19.3)^{\star \star \star \star}$ & $13.4(11.9-19.3)$ \\
\hline
\end{tabular}

${ }^{\star \star} P<0.01,{ }^{* \star \star} P<0.001$.
Table 3 Correlation matrix between total and spinal BMD and endocrine variables in bulimic women. Values are given as correlation coefficients.

\begin{tabular}{lcc}
\hline & BMD total body & BMD spine \\
\hline $\begin{array}{l}\text { Present menstrual } \\
\text { disturbance }\end{array}$ & -0.15 & -0.06 \\
$\begin{array}{l}\text { Duration of present } \\
\text { menstrual disturbance }\end{array}$ & -0.17 & -0.03 \\
History of amenorrhea & $-0.37^{\star *}$ & $-0.35^{\star *}$ \\
E2 (pmol//)\# & 0.03 & 0.21 \\
Cortisol (nmol/l) & $-0.23^{*}$ & $-0.29^{\star}$ \\
Testosterone (nmol/l) & 0.06 & $0.27^{\star}$ \\
fT (pmol/l) & 0.02 & $0.25^{\star}$ \\
IGF-I $(\mu \mathrm{g} / \mathrm{l})$ & -0.10 & 0.01 \\
TSH (mlU//)\# & 0.06 & 0.08 \\
fT4 (pmol/l)\# & 0.18 & 0.12 \\
\hline
\end{tabular}

"Log-transformed values. ${ }^{*} P<0.05,{ }^{* *} P<0.01$.

$P<0.05)$ than controls. None of the controls had a history of anorexia nervosa.

Correlations between total and spinal BMD and nutrition-related variables in women with bulimia are shown in Table 4. BMI was positively correlated and previous anorexia nervosa negatively correlated with total and spinal BMD $(P<0.01-0.001)$. BMD was not significantly associated with type of diagnosis (bulimia nervosa or EDNOS) or with smoking.

Results from the multiple regression analysis of spinal BMD in bulimic women are summarized in Table 5. Three different models with significant independent variables are presented, a model of endocrine variables, nutrition-related variables, and endocrine- and nutrition-related variables in combination. A history of amenorrhea, cortisol, and $\mathrm{fT}$ were endocrine variables that were independently associated with spinal BMD. Nutrition-related determinants were BMI and past anorexia nervosa. In the combined multiple regression model, previous anorexia nervosa was the only significant determinant of spinal BMD, accounting for $35 \%$ of the variance.

There were correlations between independent endocrine- and nutrition-related variables. A history of amenorrhea was significantly associated with previous anorexia nervosa $(r=0.47, P<0.001)$, whereas

Table 4 Correlation matrix between total and spinal BMD and nutrition-related variables in bulimic women. Values are given as correlation coefficients.

\begin{tabular}{lcc}
\hline & BMD total body & BMD spine \\
\hline BMI $\left(\mathrm{kg} / \mathrm{m}^{2}\right) \#$ & $0.34^{\star *}$ & $0.47^{\star \star \star}$ \\
Type of diagnosis & -0.17 & -0.24 \\
$\quad$ (BN/EDNOS) & & \\
Debut of bulimia & 0.04 & 0.06 \\
Duration of bulimia & 0.14 & 0.02 \\
History of anorexia nervosa & $-0.49^{\star \star *}$ & $-0.51^{\star \star \star}$ \\
Smoking & -0.06 & -0.12 \\
\hline
\end{tabular}

${ }^{\#}$ Log-transformed values. ${ }^{* \star} P<0.01,{ }^{* \star \star} P<0.001$. 
Table 5 Forward stepwise multiple regression analyses of endocrine- and nutrition-related determinants of spinal BMD in bulimic women. Values are regression coefficients.

\begin{tabular}{lccc}
\hline & Model of endocrine variables & $\begin{array}{c}\text { Model of nutrition-related } \\
\text { variables }\end{array}$ & $\begin{array}{c}\text { Model of endocrine- and } \\
\text { nutrition-related variables }\end{array}$ \\
\hline $\begin{array}{l}\text { Endocrine factors } \\
\text { History of amenorrhea }\end{array}$ & $-0.32^{* *}$ & - & - \\
Cortisol $(\mathrm{nmol} / \mathrm{l})$ & $-0.28^{\star *}$ & - & - \\
$\mathrm{fT}(\mathrm{nmol} / \mathrm{l})$ & $0.26^{*}$ & - & - \\
Nutrition-related factors & - & $0.32^{\star *}$ & - \\
BMI $\left(\mathrm{kg} / \mathrm{m}^{2}\right) \#$ & - & $-0.40^{\star \star}$ & $-0.34^{\star *}$ \\
History of anorexia nervosa & 0.23 & 0.35 & 0.35 \\
Total adjusted $R^{2}$ & & \\
\hline
\end{tabular}

Total adjusted $R$ square $\left(R^{2}\right)$ for each model is presented. ${ }^{*}$ Log-transformed values. ${ }^{\star} P<0.05,{ }^{\star *} P<0.01,{ }^{\star * \star} P<0.001$.

cortisol was negatively correlated and fT positively correlated with BMI $(r=-0.37$ and $0.42, P<0.001$ respectively).

\section{Discussion}

We found low spinal BMD and increased frequency of osteopenia in the total body in bulimic women compared with controls. Low BMD in bulimics is in accordance with some studies (1-4). but not with others (5-7). Compared with most previous studies, this study involves a large group of bulimics, which enabled the analysis of endocrine- and nutrition-related variables determining BMD in these patients.

Hormones and endocrine factors are known to be important for bone metabolism. Endocrine effects are seen particularly in bone with high turnover, i.e. trabecular bone, such as in the spine. Our bulimics had normal BMD in legs, containing mainly cortical bone, but low BMD in the spine, suggesting that there are endocrine influences of importance for trabecular bone in these women. Several endocrine variables differed between bulimics and controls. The frequency of present menstrual disturbance among bulimics was high, and $\mathrm{E}_{2}$ levels were lower than in the controls. These factors were not significantly related to BMD, although $\mathrm{E}_{2}$ showed a tendency towards a positive association with spinal BMD. However, a history of amenorrhea, probably reflecting previous periods of hypoestrogenism, was strongly negatively correlated with total and spinal BMD. Since most bulimics with present menstrual disturbance had oligomenorrhea, it seems that this condition has less influence on bone mass than previous amenorrhea. The duration of menstrual disturbance should also be of importance. However, we found no significant association between duration of present menstrual disturbance and BMD. It was not possible to obtain reliable data regarding the total duration of past amenorrhea.

In accordance with numerous previous studies (15, 17), elevated cortisol levels were found in the bulimic women and cortisol was negatively correlated with total and spinal BMD. We also found significant positive correlations between testosterone and $\mathrm{fT}$ on the one hand, and spinal BMD on the other hand. However, in contrast to previous reports (18-20), patients and controls did not differ in testosterone and fT levels. Another anabolic factor, which may affect bone mass is IGF-I (29). However, there was no association between IGF-I and BMD and there were no differences in serum levels of IGF-I between bulimic patients and controls, confirming previous findings of Levy and Malarkey (30). Finally, bulimics had significantly lower $\mathrm{fT}_{4}$ levels than controls, but there was no association between BMD and thyroid hormones.

Multivariate regression analysis of endocrine variables demonstrated that a history of amenorrhea, levels of cortisol and fT were significant predictors of spinal BMD in bulimic women, accounting for $23 \%$ of the variance of BMD. Among these variables, a history of amenorrhea showed the strongest correlation with spinal BMD. The association between amenorrhea and low bone mass is well known (31). The mechanism is attributed to estrogen deficiency, which leads to an increased bone resorption, since estrogen has osteoprotective effects through specific estrogen receptor actions $(32,33)$. Cortisol was also highly negatively correlated with spinal BMD. Glucocorticoids have complex direct and indirect effects on bone mass. The major direct effect on bone is a decrease in its formation (34). Glucocorticoids can also stimulate bone resorption by enhanced osteoclast differentiation, as well as by secondary hyperparathyroidism (34). Since the bulimics had increased levels of cortisol, this might to some extent explain their low spinal BMD. On the other hand, androgens have anabolic effects on the skeleton, as shown in hyperandrogenic women with high BMD compared with controls (35-37). However, since our bulimic women had normal levels of testosterone and fT comparable to those of controls, an anabolic effect of androgens could not compensate for effects of hypercortisolism on bone mass.

The associations between BMD and endocrine factors in the bulimic women were not as strong as the correlations between BMD and nutrition-related factors, i.e. BMI and a history of anorexia nervosa. The positive association between BMI and bone mass is well known 
(38). Furthermore, previous anorexia nervosa has been shown to have a strong negative influence on BMD in bulimic women. In accordance with previous studies, we found that almost $25 \%$ of the bulimic women had a history of anorexia nervosa (8). Those bulimics had significantly lower BMD than controls, whereas bulimics without such history had normal BMD. This important finding, also shown in some previous studies (3, 39), may explain the divergent results concerning BMD in bulimic women (vide supra). The strong influence of previous anorexia nervosa on spinal BMD was further supported by the multiple regression analysis. The analysis showed that all endocrine variables and also BMI disappeared in the combined model and only previous anorexia nervosa remained significant, accounting for $35 \%$ of the variance in spinal BMD. Endocrine variables related to BMD seem to be secondary determinants that are dependent on previous anorexia nervosa and BMI.

What is the explanation for the low BMD in bulimics with previous anorexia nervosa? Actual bone density in adults depends on peak adult bone mass and subsequent bone loss. The most common age of onset of anorexia nervosa, the mid to late teens, corresponds to the time, at which maximum skeletal mass is gained (40). Conditions including caloric insufficiency, such as anorexia nervosa, will negatively affect bone formation during this sensitive period of life, and may result in a low peak bone mass. Anorexia nervosa is also associated with several endocrine disturbances that probably contribute to inhibited skeletal development. We found a strong correlation between previous anorexia nervosa and a history of amenorrhea. Estrogen deficiency leading to amenorrhea during anorexia nervosa may, therefore, also cause increased bone resorption. Although better nutrition and subsequent weight gain can improve BMD in anorectic patients $(9,10)$, there may still be a failure to attain normal bone mass after recovery from anorexia nervosa.

In conclusion, the results of the present study evidently demonstrate that a history of anorexia nervosa is by far the most decisive factor for low bone mass in bulimic patients. Endocrine variables related to BMD seem rather to be secondary determinants dependent on previous anorexia nervosa and BMI. Despite showing hormonal aberrations when compared with controls, bulimics without previous anorexia nervosa have normal bone mass. A varying element of past anorexia in the different study populations of bulimics may explain the divergent results obtained in previous studies. Bulimics with a history of anorexia nervosa should be considered a risk group for osteoporosis and nontraumatic fractures later in life. It is, therefore, important to evaluate BMD in this subgroup of bulimics in order to take relevant action, such as optimizing nutritional intake, to prevent further bone loss.

\section{Acknowledgements}

This work was supported by the Council Resource Center for Eating Disorders and Karolinska Institutet, Stockholm, Sweden. The authors thank Malin Levin, Anna Lindström and Vilhelmina Rommel for psychiatric evaluation, and Anna Karlsson, Yvonne Pierre and Birgitta Byström for skilful technical assistance. The authors also thank Elisabeth Berg for statistical assistance.

\section{References}

1 Howat PM, Varner LM, Hegsted M, Brewer MM \& Mills GQ. The effect of bulimia upon diet, body fat, bone density and blood components. Journal of the American Dietetic Association 198989 929-934.

2 Joyce JM, Warren DL, Humphries LL, Smith AJ \& Coon JS. Osteoporosis in women with eating disorders: comparison of physical parameters, exercise and menstrual status with SPA and DPA evaluation. Journal of Nuclear Medicine 199031 325-331.

3 Newton JR, Freeman CP, Hannan WJ \& Cowe S. Osteoporosis and normal weight bulimia - which patients are at risk? Journal of Psychosomatic Research 199337 239-247.

4 Baker D, Roberts R \& Towell T. Factors predictive of bone mineral density in eating-disordered women: longitudinal study. International Journal of Eating Disorders 200027 29-35.

5 Newman MM \& Halmi KA. Relationship of bone density in anorexia nervosa and bulimia. Psychiatry Research 198929 105112.

6 Sundgot-Borgen J, Bahr R, Falch JA \& Sundgot-Schneider L. Normal bone mass in bulimic women. Journal of Clinical Endocrinology and Metabolism $1998 \mathbf{8 3} 3144-3149$.

7 Zipfer S, Seibel MJ, Löwe B, Beumont PJ, Kasperk C \& Herzog W. Osteoporosis in eating disorders: a follow-up study of patients with anorexia nervosa and bulimia nervosa. Journal of Clinical Endocrinology and Metabolism 200186 5227-5233.

8 Kaye WH, Klump KL, Frank GK \& Strober M. Anorexia and bulimia nervosa. Annual Review of Medicine 200051 299-313.

9 Legroux-Gerot I, Vignau J, Collier F \& Cortet B. Bone loss associated with anorexia nervosa. Joint Bone Spine 200572 $489-495$.

10 Katzman DK. Osteoporosis in anorexia nervosa: a brittle future? Current Drug Targets CNS Neurological Disorders 20032 11-15.

11 Abraham S. Sexuality and reproduction in bulimia nervosa patients over 10 years. Journal of Psychosomatic Research 1989 44 491-502.

12 Gendall KA, Bulik CM, Joyce PR, McIntosh VV \& Carter FA. Menstrual cycle irregularity in bulimia nervosa. Associated factors and changes with treatment. Journal of Psychosomatic Research $200049409-415$.

13 Crow SJ, Thuras P, Keel PK \& Mitchell JE. Long-term menstrual and reproductive function in patients with bulimia nervosa. American Journal of Psychiatry 2002159 1048-1050.

14 Monteleone P, Martiadis V, Colurico B \& Maj M. Leptin secretion is related to chronicity and severity of the illness in bulimia nervosa. Psychosomatic Medicine 200264 874-879.

15 Levy AB. Neuroendocrine profile in bulimia nervosa. Biological Psychiatry 198925 98-109.

16 Mortola JF, Rasmussen DD \& Yen SS. Alterations in the adrenocorticotropin-cortisol axis in normal weight bulimic women: evidence for a central mechanism. Journal of Clinical Endocrinology and Metabolism 198968 517-522.

17 Bailer UF \& Kaye WH. A review of neuropeptide and neuroendocrine dysregulation in bulimia nervosa. Current Drug Targets CNS Neurological Disorders 20032 53-59. 
18 Sundblad C, Bergman L \& Eriksson E. High levels of free testosterone in women with bulimia nervosa. Acta Psychiatrica Scandinavia 199490 397-398.

19 Cotrufo P, Monteleone P, d'Istria M, Fuschino A, Serino I \& Maj M. Aggressive behavioral characteristics and endogenous hormones in women with bulimia nervosa. Neuropsychobiology 200042 58-61.

20 Monteleone P, Luisi M, Casarosa E, Monteleone P, Ioime R, Genazzani AR \& Maj M. Plasma levels of neuroactive steroids are increased in untreated women with anorexia nervosa or bulimia nervosa. Psychosomatic Medicine 200163 62-68.

21 Schweiger U, Pirke KM, Laessle RG \& Fichter MM. Gonadotropin secretion in bulimia nervosa. Journal of Clinical Endocrinology and Metabolism 199274 1122-1127.

22 Altemus M, Hetherington MM, Kennedy B, Licino J \& Gold PW. Thyroid function in bulimia nervosa. Psychoneuroendocrinology 199621 249-261.

23 Pantazi H \& Papapetrou PD. Changes in parameters of bone and mineral metabolism during therapy for hyperthyroidism. Journal of Clinical Endocrinology and Metabolism 200085 1099-1106.

24 Clinton DN \& Glant R. The eating disorders spectrum of DSM-IIIR. Journal of Nervous and Mental Disease $1992180244-250$.

25 Nuti R, Martini G, Righi G, Frediani B \& Turchetti V. Comparison of total-body measurements by dual-energy X-ray absorptiometry and dual-photon absorptiometry. Journal of Bone Mineral Research $19916681-687$.

26 Brismar T \& Ringertz H. Effect of bone density of the head on total body DEXA measurements in 100 healthy Swedish women. Acta Radiologica 199637 101-106.

27 Writing group for the ISCD Position Development Conference. Diagnosis of osteoporosis in men, premenopausal women, and children. Journal of Clinical Densitometry 20047 17-26.

28 Södergård R, Bäckström $\mathrm{T}$, Shanbag $\mathrm{V}$ \& Carstensen $\mathrm{H}$ Calculation of free and bound fractions of testosterone and estradiol-17 $\beta$ to plasma proteins at body temperature. Journal of Steroid Biochemistry 198218 801-804.

29 Rosen CJ \& Bilezikian JP. Anabolic therapy for osteoporosis. Journal of Clinical Endocrinology and Metabolism 200186 957-964.

30 Levy AB \& Malarkey WB. Growth hormone and somatomedin-C in bulimia. Psychoneuroendocrinology 198813 359-362.
31 Gordon CM \& Nelson LM. Amenorrhea and bone health in adolescents and young women. Current Opinion in Obstetrics and Gynecology 200315 377-384.

32 Nilsson S, Mäkelä S, Treyter E, Tujague M, Thomsen J, Andersson G, Enmark E, Pettersson K, Warner M \& Gustafsson J-Å. Mechanisms of estrogen action. Physiological Review $2001 \mathbf{8 1}$ 1535-1565.

33 Lanyon L, Armstrong V, Ong D, Zaman G \& Price J. Is estrogen receptor alpha key to controlling bones' resistance to fracture? Journal of Endocrinology $2004 \mathbf{1 8 2} 183-191$.

34 McIlwain HH. Glucorticoid-induced osteoporosis: pathogenisis, diagnosis and management. Preventive Medicine $2003 \mathbf{3 6}$ 243-249.

35 Meema S \& Meema HE. Evaluation of cortical bone mass, thickness and density by z-scores in osteopenic conditions and in relation to menopause and estrogen treatment. Skeletal Radiology $1982 \mathbf{8}$ 259-268.

36 Zborowski JV, Cauley JA, Talbott EO, Guzick DS \& Winters SJ. Clinical Review 116: Bone mineral density, androgens, and the polycystic ovary: the complex and controversial issue of androgenic influence in female bone. Journal of Clinical Endocrinology and Metabolism 200085 3496-3506.

37 Zborowski JV, Talbott EO \& Cauley JA. Polycystic ovary syndrome, androgen excess, and the impact on bone. Obstetrics and Gynecology Clinics of North America 200128 135-151.

38 Reid R. Relationships among body mass, its components, and bone. Bone 200231 547-555.

39 Anderson AE, Woodward PJ \& LaFrance N. Bone mineral density of eating disorder subgroups. International Journal of Eating Disorders $1995 \mathbf{1 8} 335-342$.

40 Gilsanz V, Varterasian M, Senec MO \& Cann CE. Quantitative spinal mineral analysis in children. Annals of Radiology 198629 380-382.

Received 12 January 2006

Accepted 5 May 2006 